\title{
DANÇA PARA EDUCAR E ENTRETER, O CURSO NATÁLIA LESSA EM BELO HORIZONTE (1928-1960)
}

Recebido em: 18/08/2015

Aceito em: 04/03/2016

\author{
Elisângela Chaves ${ }^{1}$ \\ Universidade Federal de Minas Gerais (UFMG) \\ Belo Horizonte $-\mathrm{MG}-$ Brasil
}

\begin{abstract}
RESUMO: Natália Lessa cria em 1934, o primeiro espaço privado e especializado no ensino da dança para meninas em Belo Horizonte - MG. Ela ministra aulas e realiza apresentações coreográficas com suas alunas em espaços públicos num período marcado por inovações nos modos de ser e de viver na cidade, um conjunto de alterações para a educação feminina no período. A partir das análises de fontes diversificadas pudemos identificar a intencionalidade pedagógica do Curso em educar, através da dança, a feminilidade seguindo ideários em circulação e promovendo uma alternativa de entretenimento na cidade. Uma prática que fomentou a formação de plateias seja nos teatros ou em outros espaços de apresentação, e a apreciação da dança através da divulgação nas revistas e jornais.
\end{abstract}

PALAVRAS CHAVE: Atividades de Lazer. Dança. Dança/História.

\section{DANCE TO EDUCATE AND ENTERTAIN THE NATÁLIA LESSA COURSE IN BELO HORIZONTE (1928-1960)}

ABSTRACT: Natalia Lessa create 1934, the first private space specializing in dance education for girls in Belo Horizonte - MG. She teaches classes and performs choreographic performances with his students in public spaces in a period marked by innovations in the ways of being and living in the city, a number of changes for female education in the period. From the analysis of different sources we can identify the pedagogical intention of the course to educate through dance, the femininity following ideals in circulation and promoting an alternative entertainment in the city. A practice that encouraged the formation of audiences whether in theaters or other areas of presentation and appreciation of dance through the dissemination in magazines and newspapers.

KEYWORKS: Leisure Activities. Dancing. Dancing/History.

\footnotetext{
${ }^{1}$ Este artigo faz parte da pesquisa de doutoramento em Educação na UFMG que foi parcialmente financiada pela Fapemig.
} 


\section{Introdução}

O cenário que figura esta narrativa histórica tem na ambiência cultural da cidade de Belo Horizonte e na criação, em 1934, e consolidação do Curso Natália Lessa, importantes indícios para a tessitura das relações entre seu ensino de dança como educação feminina e entretenimento para população local, nesta cidade nascida à luz da República, projetada para legitimar o desejo e a expressão de um novo tempo. A delimitação do recorte temporal desta pesquisa, datada de 1928 ao ano de 1960, foi uma escolha diante de um conjunto de acontecimentos que envolveram a vida e as atividades profissionais da professora Natália Lessa, fundadora da primeira escola de dança para meninas na capital mineira. Formada na escola Normal do Colégio Sagrado Coração de Jesus no ano de 1928, deu início à sua trajetória na docência como estagiária na cadeira de gymnastica no Grupo Escolar Barão do Rio Branco. Acompanhamos sua carreira até 1960, ano de sua aposentadoria no Grupo Escolar, e o consequente afastamento das atividades escolares. Após essa data, ela passa a se dedicar unicamente à dança, já em uma fase de maturidade profissional, com 26 anos de experiência em seu curso.

A seleção e identificação de fontes para realização desta pesquisa contou com um conjunto de "pistas" identificadas em pesquisas, acervos de imagens, entrevistas e publicações da imprensa no período em análise. Elegemos a produção da imprensa local como referência, entendendo-a como um instrumento privilegiado nesse momento histórico de disseminação de ideários educacionais para a modernidade e com grande influência sobre os debates cotidianos em circulação na vida cultural da cidade. Além dessas referências da imprensa, nas quais comumente o anúncio de práticas da professora Natália Lessa vinha acompanhado de imagens de suas alunas, também outros documentos relacionados à sua vida pessoal e profissional, como fotografias e as 
memórias de parentes, alunas e amigos foram reunidos para compor as fontes sobre sua trajetória profissional. Os depoimentos de familiares, alunas e conhecidos foram adquiridos em bancos de dados do Programa de História Oral da FAFICH/UFMG, e através de entrevista semi-estruturada pela pesquisadora. Não foi intenção desta pesquisa compor uma metodologia de análise da história oral, no sentido de construir a narrativa a partir das memórias destes sujeitos, mas sim de, a partir dessas falas, identificar indícios, comparar e contrapor informações, orientar análises, ter acesso a acervos pessoais.

O recorte temporal e a multiplicidade de questões que envolvem a História da Educação, em seus entrelaçamentos com a história de Belo Horizonte e com a história da dança nessa cidade, exigiram uma flexibilização das reflexões sobre o objeto desta pesquisa. Identificando o fluxo de mudanças que se instaura e/ou se pretende instaurar na capital mineira, dos espaços reservados às pessoas, a modernidade será tomada aqui como um tempo de eclosão de descontinuidades. Para refletir sobre esse quesito nos orientamos pelas reflexões de Walter Benjamin, o cenário de modernidade no qual está inserida a cidade. Para Benjamin,

Articular historicamente o passado não significa conhecê-lo "como ele de fato foi". Significa apropriar-se de uma reminiscência, tal como ela relampeja no momento de um perigo. [...] O perigo ameaça tanto a existência da tradição como os que a recebem (BENJAMIN, 1996, p.224).

Problematizar o ensino da dança em sua condição passada exige a percepção de efemeridades postas, desafio inerente ao se pesquisar a apropriação dessa experiência corporal que permanece ou permaneceu nos corpos que dançaram e na memória dos que observaram. Os fatos concretos como a criação do curso, o grande número de alunas e quem foram elas na sociedade belorizontina ativam percepções que reverberam do 
passado para o presente. Um desafio à memória, ao registro e à nossa própria compreensão sobre a professora Natália Lessa, o ensino da dança para meninas e a ambiência cultural na cidade de Belo Horizonte, pensada e planejada para ser um centro urbano irradiador da modernidade republicana.

\title{
Belo Horizonte, a Modernidade e a Busca de Novas Sensibilidades
}

A capital mineira, com pretensões de destaque nacional, para além de uma vitrine moderna de praças, ruas, avenidas e edificações, teve também em seus habitantes um foco de atenção. A materialização do projeto de modernidade só poderia se concretizar mediante o cultivo de novas maneiras e modos de se viver na cidade. Questões que passavam necessariamente pela adaptação, aprendizagem e (re) invenção de comportamentos. Os corpos que ocupavam os espaços precisavam se mover e se postar em novos ritmos, com elegância, com higiene. As atitudes corporais singulares precisavam desenvolver um comportamento social de pertencimento à essa ambiência, principalmente quando observadas nos espaços públicos. Os sujeitos e seus grupos sociais necessitavam de outra sensibilidade para ser e estar na intencionada cidade moderna, naquele mundo urbano. (MORENO; VAGO, 2011, p. 68-69).

\begin{abstract}
As sensibilidades seriam, pois, as formas pelas quais indivíduos e grupos se dão a perceber, comparecendo como um reduto de tradução da realidade por meio das emoções e dos sentidos. Nessa medida, as sensibilidades não só comparecem no cerne do processo de representação do mundo, como correspondem, para o historiador da cultura, àquele objeto a capturar no passado, à própria energia da vida (PESAVENTO, 2005, p. 57).
\end{abstract}

Como cita Sandra Pesavento, "As sensibilidades são uma forma do ser no mundo e de estar no mundo, indo da percepção individual à sensibilidade partilhada." (PESAVENTO, 2004, p. 1). Dessa forma, todo o ambiente de vivência social deveria 
ser reformado, propiciando novas experiências e uma nova apreciação desses espaços. Segundo Clarice Nunes (2000), “[...] os espaços de aprendizagem se multiplicaram: não apenas a sala de aula, mas também as bibliotecas, os laboratórios, a rádio-educativa, os teatros, os cinemas, os salões de festa, os pátios, as quadras de esporte, os refeitórios, as ruas, as praças e os estádios desportivos”. (NUNES, 2000, p. 374-375).

Assim, apesar do alto investimento na educação moldada para a instituição escolar formal, outras possibilidades educacionais também ampliam suas intervenções no espaço cultural da cidade. Despertar essa nova sensibilidade para os tempos modernos exigia uma processual educação, que precisava ser incutida desde a infância para cultivar uma "nova" população, em interação com novas práticas escolares e culturais. De finais do século XIX e início do século XX,

[...] ganha destaque as preocupações em torno de como incorporar culturalmente os sujeitos sociais em suas diferentes manifestações, na perspectiva da formação de homens e mulheres civilizados e educados. Fundamentados na tese da homogeneidade cultural e da formação da opinião pública, a cultura urbana e a cultura escolar elaboradas nessa época lida com a diversidade material e social dos indivíduos produzindo uma tensão permanente com os elementos fundantes da sociedade de então: razão, propriedade e indivíduo (VEIGA, 2000; FARIA FILHO, 1997, p. 204).

Mas intenções e prescrições não traduzem necessariamente as práticas vividas, experienciadas em um dado momento histórico. Além dos discursos e intervenções na capital mineira obstinada na aquisição de hábitos e costumes de referência moderna, José Murilo de Carvalho argumenta que Belo Horizonte, apesar de profundamente marcada pela intenção do novo, e deste moderno, vivia ambiguamente uma densa valorização da conservação de tradições. Após a imposição do novo regime, o Estado mineiro assumiu um programa de modernização conservadora. "A relação do Estado com o indivíduo era uma combinação de repressão e paternalismo. [...] Deturpava-se, ao 
mesmo tempo, a boa modernidade e a boa tradição". (CARVALHO, 1999, p. 127). As resistências sociais às inovações, a própria concepção imposta por militares e técnicos, incorporada pelo ideário do Estado Novo, desconsiderava a dimensão da iniciativa individual e o mecanismo de controle dessa modernização era solucionado com o autoritarismo.

A força da tradição não se revelava somente nas resistências ao que se considerava moderno, e que eram muitas coisas nesse momento, mas também na reação às interferências do cotidiano, sobretudo da vida doméstica. Os padrões de moralidade familiar eram fortes e rígidos, especialmente os aplicados às mulheres (CARVALHO, 1999). A feminilidade a ser caracterizada como moderna e vinculada aos princípios culturais dessa cidade encontravam-se num campo de limites tênues entre a recepção e apropriação do novo e a conservação das tradições. Nessa cena de disputas sociais e culturais na cidade, entre a modernidade e a tradição, os projetos educacionais foram focos de grande investimento.

Mas como educar esses corpos? Como cultivar essas sensibilidades? Como identificar que feminilidade ? A problematização dessas questões em um tempo passado nos levaram cada vez mais a pensar nas ambiguidades contidas ao entorno de nosso objeto de pesquisa. As sensibilidades evocam as relações entre as pessoas, as experiências comuns que permitem reações semelhantes, que não devem ser confundidas com uma simples reação automática ou uníssona. A vida afetiva é individual e subjetiva, mas manifestações compartilhadas se difundem contagiando miméticamente uns aos outros, não como reação automática ao mundo exterior, mas como sensibilidades relacionadas na manifestação de emoções. Nossas reflexões a cerca da educação do corpo, perpassam por essa noção. Para Soares, 
[...] os corpos são educados por toda realidade que os circunda, por todas as coisas com as quais convivem, pelas relações que se estabelecem em espaços definidos e delimitados por atos de conhecimento. Uma educação que se mostra como face polissêmica e se processa de um modo singular: dar-se não só por palavras, mas por olhares, gestos, coisas, pelo lugar onde vivem (SOARES, 2006, p.110).

Diferentes estratégias foram disseminadas para promoção de uma educação corporal feminina, para constituição de uma outra mulher que, consequentemente, seria uma nova mãe, uma nova professora, capaz de educar em seu lar, em sua sala de aula, e nos espaços públicos por onde elas passam a circular cada vez mais. Sensibilidades cultivadas individualmente, mas inter-relacionadas e que difundiriam um ideário. As discussões sobre a educação feminina são respaldadas com forte menção à saúde e à moral, uma definição clara de sua posição social no período em que a maternidade era o horizonte desejável para o sexo feminino. Na busca da constituição de uma mulher moderna, as práticas corporais tiveram importante destaque; traduziam inovações nos divertimentos, no esporte em ascensão e nas práticas cotidianas.

A criação do Curso de Dança Natália Lessa, em 1934, foi uma iniciativa que se destacou nesse cenário dada sua preocupação com a educação do corpo, em especial do corpo feminino. O ideário da completa reforma do espírito público não poderia negligenciar a importância da educação corporal feminina que, na cidade de Belo Horizonte, ainda não era contemplada como já acontecia nos grandes centros de referência nacional à época, como Rio de Janeiro e São Paulo.

A ênfase da citação da cidade como mediadora da produção de Natália Lessa não se dá por mera delimitação contextual. Foram as articulações possíveis nessa ambiência que permitiram à Natália e a suas alunas se estabelecerem e se tornarem parte da história local. Segundo Arnaldo L. de Alvarenga, o trabalho de Natália Lessa 
propiciou as condições iniciais que construíram a formação do campo da dança profissional em Belo Horizonte, a dança foi introduzida em outros espaços, fora a escola e os salões de festa. Através de seu curso iniciou-se a tradição local de festivais e a formação de um público frequentador de seus espetáculos nos auditórios e teatros da cidade. Ainda segundo o autor, sem formação específica em dança, na extensão de seu trabalho de ginástica para espaços externos às escolas públicas, ela passou a lecionar uma fusão da ginástica com danças populares, fazendo, inclusive, uma incursão pelo próprio balé clássico, apoiando-se em sua autoridade como professora de ginástica, usufruindo de sua imagem de respeitabilidade e competência já reconhecidas. (ALVARENGA, 2002, p. 92-96).

O fato de uma mulher organizar em Belo Horizonte um espaço educativo, sob a égide do Estado, dada sua localização Salão Nobre do primeiro Grupo Escolar e destinado à infância e à juventude femininas, sinaliza o reconhecimento da dança como prática viável na ampliação da presença da mulher nas cenas públicas, da valorização de sua preparação para essa exposição. À cena republicana mineira, já habituada ao entretenimento das festividades escolares e cívicas, acrescentam-se os festivais das jovens alunas do Curso de Dança Natália Lessa. Era uma nova convivência, no cotidiano do Curso e nas apresentações públicas, que expunha uma novidade no cenário cultural da cidade.

\section{Educação e Entretenimento: o Curso Natália Lessa em Cena}

As dançarinas... crianças que ao seu tempo materializaram, a partir de seus corpos, diferentes formas a dança em Belo Horizonte, foram identificadas nas fotografias, nas reportagens, nas memórias. O Curso era oferecido para meninas de 3 a 
12 anos de idade. Há uma recorrência no registro da participação de ex-alunas nos festivais. Segundo alguns relatos, essas ex-alunas eram meninas que tendo ultrapassado os 12 anos, já “estavam mocinhas”. Portanto, se apresentavam como participação especial e auxiliavam a professora Natália Lessa nos ensaios, como consta nos programas de espetáculos, reportagens e depoimentos das alunas ${ }^{2}$.

Mas a rede de sociabilidade constituída pelo curso não se restringia ao convívio das alunas. Em um período em que a vida pública da mulher ainda era restrita, mães, babás, irmãs, avós e tias das alunas tinham no acompanhamento das crianças a criação de um espaço de convivência majoritariamente feminino. Levar as alunas, aguardar o término da aula, bordar figurinos e acessórios eram ações que faziam parte da ambiência do curso para quem acompanhava as atividades. Em 1960, o jornal O Diário relata: "Diversas mães têm gosto em acompanhar as filhas e fazem questão de assistir às aulas. Das 80 alunas do Curso, 40 têm a idade de 3 a 6 anos." (O DIÁRIO, 17 de setembro, 1960, p.5 ). Havia uma intensa participação das mães; Lélia Almeida Magalhães Pinto da Cunha se lembra destas participações:

[...] as mães ficavam todas atrás dos palcos, pra vestir as meninas, pra trocar, era gente demais. Pessoas elegantes da cidade, mais ricas da cidade, todo mundo que tinha alguma coisa boa. Eram as filhas, as netas, eram alunas da Natália. Era uma vantagem muito grande, era muito séria, ela era uma pessoa muito séria, numa época que as meninas eram só mimadas.(CUNHA, 2012).

Ao mesmo tempo em que contemplava a responsabilidade educacional das mães, de selar e guiar a boa educação das filhas, o convívio feminino nos "bastidores do curso" consentia um lugar de trocas restritas ao universo feminino. Um espaço

\footnotetext{
${ }^{2}$ No programa do Festival das Alunas do Curso "Natália Lessa", em 1/5/1943, no Cine Brasil, consta entre as coreografias na segunda parte: "3) Escrava (interpretação do prelúdio de Rachmaninoff) - exaluna Maria do Carmo Gonçalves [...] 6) Valsa das Flores de Tschaikowsky - ex- alunas e solo por Ceci Tompa [...] 8) Pele Vermelha (típico) - ex- alunas. Ainda no programa é apresentado o elenco e ao final: "Ex-alunas: Maria do Carmo Gonçalves - Maria Inês e Amariles Bolivar - Maria Amalia Menegal Belkiss e Mára Vasconcelos e Vanessa Leite Neto.
} 
"autorizado", sem riscos, mas com porosas possibilidades para uma rede de sociabilidade. Um ponto de encontro, um tempo livre de circulação pelas ruas, de visitas rápidas; a geração de outros vínculos de convivência e amizade teciam aí outras possibilidades sociais de circulação fora de seus lares e para além dos vínculos familiares.

A professora Natália Lessa fomentava esse grupo, em sua maioria mães que estabeleciam uma parceria junto às atividades do Curso. Essas mães colaboravam com a realização de obras de caridade, com missas comemorativas do aniversário do Curso, com a confecção e detalhamento dos figurinos, com a organização de apresentações, além do apoio para aquisição de espaços para os festivais, vendas e distribuição de ingressos. Uma relação exposta por vezes na imprensa com demonstrações de carinho e respeito à professora, por parte das alunas e suas famílias. Em 1960, após ter recebido agressivas críticas do professor e bailarino Carlos Leite, em relação a sua metodologia de trabalho e formação profissional, foi publicada no Jornal $O$ Diário uma matéria intitulada "Alunas de dança homenageiam Dona NATÁLIA LESSA", que iniciava dizendo:

Diversas homenagens foram prestadas a D. NATÁLIA LESSA pelas alunas e famílias do Curso de Dança por ela dirigido e que tem por finalidade o desenvolvimento da graça feminina e da sociabilidade das meninas que o frequentam (O DIÁRIO, 17 de setembro de1960)

O ensino da dança proposto e efetivado por Natália Lessa conquistou empatia e confiabilidade das famílias belorizontinas que, durante gerações, confiaram a ela parte da educação de suas filhas. Irma Volpe, irmã de uma das cunhadas de Natália Lessa, nascida em 1927, não foi sua aluna, mas conviveu com ela no âmbito familiar e declara que ela era uma pessoa, 
[...] muito, muito conhecida, exatamente da sociedade, da nata da sociedade, porque para fazer balé, até hoje para fazer balé os custos são altos, né. E não é qualquer criança que pode se colocar em um balé para começar a fazer né.

[...] mas ela frequentava a nata da sociedade, a Natália era da nata da sociedade de Belo Horizonte. Ela era muito bem relacionada que eu saiba. Ela era muito bem assim... recebida em todas as casas das mães, dos pais das alunas delas e ela era uma pessoa assim, no meu ponto de vista, muito agradável, conversava muito bem, muito bacana a Natália, eu achava (VOLPE, 2012).

Lêda Gontijo foi aluna de Natália no Grupo Escolar nas aulas de Gymnastica, e acompanhou suas atividades no Minas Tênis, onde era atleta de tênis. Segundo ela, apesar do convívio com essa sociedade elitizada, acima citada, ela não fazia parte das elites, trabalhava para elas. E isso tinha uma diferença em relação às mulheres das elites, que não trabalhavam. Ainda segundo Lêda Gontijo, "Ela era muito conceituada e profissional. A mulher que saía dos cânones morais, ela era completamente alijada da sociedade.” (GONTIJO, 2011). E Natália era apta educadora dessas elites, um mérito reconhecido socialmente àquela época.

Nas entrevistas realizadas com as alunas, quando perguntadas se apesar da apreciação e valorização da sociedade sobre o Curso, as pessoas tinham dúvida sobre as benesses do Curso para a educação das meninas, se estranhavam a exposição das filhas, Maria José Lemos, aluna na década de 40, respondeu:

Não, mesmo. Porque essa turma aí, que frequentava lá, não eram as famílias que tinham poder, eram as famílias que tinham os pais com uma visão mais moderna, mais pra frente. $\mathrm{E}$ todo mundo dava valor quando ela chegou. É tanto que o Curso pegou e durou muito tempo. [...] mais você vê as alegrias das mães acompanhando nas fotos. No final como eu te falei, virou uma família grande que todo mundo compartilhava da mesma ideia, do valor daquilo, do mesmo nível, era uma coisa que todo mundo ficava feliz, porque o festival era muito falado a gente distribuía convite para todo mundo. Era um acontecimento o festival dela (LEMOS, 2011). 
Nas falas das alunas é repetidamente expressa a caracterização do Curso de Dança Natália Lessa como uma família. Entendemos aí que não necessariamente as famílias possuíam homogeneidade de pensamentos e interesses, mas compunham uma identidade coletiva a partir do pertencimento ao Curso Natália Lessa. A utilização da palavra família adjetiva a proximidade e as relações de um espaço de respeito às hierarquias, às boas condutas, à aprendizagem de hábitos e posturas elegantes para o convívio social. Cabe ressaltar que essa ambiência possibilitou uma rede de sociabilidade que se integrava a diferentes eventualidades na vida social e cultural da cidade. Além dos festivais, como veremos posteriormente, as alunas se apresentavam em outros eventos na cidade relacionados a homenagens, auxílio filantrópico, comemorações em locais de importante referência na cidade: auditórios, salões, teatros, cinemas e clubes ${ }^{3}$. Nesses eventos estavam presentes, junto às alunas, representantes de suas famílias. Eline Rennó declara:

Dia de ensaio geral era dia de festa, pois passávamos todo o dia no Teatro Francisco Nunes, com nossa família assistindo na plateia a nos estimular, e durante os intervalos nos deliciávamos com o lanche que cada um levava. Hoje percebo o quanto Natália Lessa se dedicava ao convívio saudável das famílias e das alunas durante esses encontros (RENNÓ, 2010, apud, REIS, 2010, p.30).

A localidade facilitava o acesso a essa elite belorizontina, pois no seu entorno havia significativa quantidade de moradias da elite local que ali residia e estabelecia suas atividades cotidianas. A confiabilidade de uma escola dentro desse Grupo escolar, o oferecimento de uma atividade nova atinada às prescrições da educação física benéfica a uma dada formação feminina compõem um conjunto de atrativos que desde

\footnotetext{
${ }^{3}$ Como exemplo, podemos citar as notas nas colunas sociais na Revista Alterosa, geralmente com fotografia das alunas e a identificação do evento, como esta: "As pequeninas alunas da professora Natália Lessa, no festival realizado em benefício do Natal dos Pobres, no Cine Brasil, foram muito aplaudidas pelos magníficos números realizados.” (REVISTA ALTEROSA, ano III, n.22, 1942, p.30 ).
} 
1936, como no trecho de reportagem abaixo, atraiu as senhorinhas pertencentes à alta sociedade local:

\begin{abstract}
Essas gentis senhorinhas, todas pertencentes a nossa alta sociedade, executam, com a máxima perfeição, os mais diffíceis números de gymnastica, números estes que revertem em grande benefícios do corpo. Ainda hontem "O Esporte" teve a opportunidade de presenciar alguns números executados pela graciosas alunas do Curso "Nathalia Lessa", mantido pela senhorinha Nathalia Lessa a cargo de quem esta também a cadeira de gymnastica do Grupo Escolar Barão do Rio Branco. A impressão que colhemos foi a mais agradável possível $(\mathrm{O}$ ESPORTE, 19 de outubro, 1936, p.1 ).
\end{abstract}

Durante esses anos de trabalho foram muitas as alunas que passaram pelo curso. Os dados numéricos são imprecisos, generalizantes. ${ }^{4}$ Mas é fato que o Curso, no período em análise, é o mais frequentado da cidade, como atesta a reportagem apresentando uma análise quantitativa do número de alunos entre homens, mulheres e meninas que estudavam ballet na capital mineira:

[...] - são aproximadamente quatrocentos, isto se contarmos com as alunas de Natália Lessa, quase duzentas. [...] Carlos Leite tem 108 alunos e Klauss Vianna, cêrca de 90, mas ambos são unânimes em afirmar que, dêste total, apenas $10 \%$ apresenta realmente vocação para o ballet, e talentos são mesmo raríssimos (DIARIO DA TARDE, 1960, 2 cad., p.2). ${ }^{5}$

Vinte anos após essa publicação, o mesmo jornal, sob a redação da jornalista Márcia Lage publica:

A história da dança em Minas é também a história de Natália Lessa". Antes da chegada de Carlos Leite a Belo Horizonte, ela fundou seu curso livre no salão nobre do Grupo Escolar Barão do Rio Branco, no

\footnotetext{
${ }^{4}$ Alguns dados coletados junto às fontes:

- 1939(Revista Alterosa)- média de 60 alunas;

- 1943 (Programa de Festival)- 56 alunas dançando;

- 1956 (Programa de Festival)- 64 alunas dançando;

- 1960 (Jornal O Diário de Minas)- 200 alunas ano, (Jornal O Diário)- 210 alunas ano;

- 1974 (Livro biografia)- 3 mil alunas em 40 anos de curso;

- 1980 (Jornal Estado de Minas) - 5 mil alunas;

- 1983 (Jornal Estado de Minas)- 10 mil alunas em 50 anos de curso.

5 Jornal Diário da Tarde, Belo Horizonte 1960. O ballet e a cidade (I), primeira de uma série de três reportagens de Frederico Morais e Evandro Santiago.
} 
dia 17 de agosto de 1934. Ensinou mais de dez mil meninas a darem os primeiros passos no tablado, entre elas as filhas dos governadores Raul Soares, Benedito Valadares, Juscelino Kubitschek (LAGE, 9 de junho,1980, apud SANTOS, 1995, p. 193 ).

Dez mil alunas em 50 anos seria uma média de 200 alunas por ano. Apesar da identificação desse número em algumas fontes, também temos números menores, assim como uma total imprecisão em relação ao tempo de permanência das alunas no curso. A carência de dados não nos possibilita uma estimativa numérica. Mas nos dá pistas de que um elevado número de meninas fez parte do Curso. Segundo Glória Reis, em matéria intitulada "Já é Tradição na Capital”, o jornal O Diário em Revista, (196?), publica:

\begin{abstract}
Não há quem não conheça na Capital $D$. Natália Lessa ou que não tenha ouvido falar no Curso Natália Lessa que, ao contrário do que muita gente pensa, não se destina a formar bailarinas.

'Isso não é e nunca foi minha intenção', fez questão de afirmar a $\mathrm{O}$ DIÁRIO. 'A minha intenção' - esclarece Natália Lessa - 'é orientar um pouco a graça que as alunas têm. E o meu curso tem alcançado esse objetivo, tanto que a sociedade belohorizontina prestigiou de tal maneira a minha iniciativa que hoje rara é a família em que não conto com uma ex-aluna (DIARIO EM REVISTA, 196? ).
\end{abstract}

Essa dimensão de ampla abrangência na sociedade belorizontina, durante quase 50 anos de trabalho, e sua popularidade e reconhecimento, fez do nome de Natália Lessa e de seu curso uma referência mineira. Em artigo de valorização da vida cultural, a Revista Alterosa, em 1943, publica reportagem destacando as atividades de cunho artístico cultural que aconteciam na cidade, intitulada "O esplendor Cultural". Nela constava uma fotografia de aproximadamente meia página das alunas do Curso enfileiradas e uniformizadas, segurando uma bandeira com a sigla CNL (Curso Natália Lessa) em uma escadaria, fazendo referências ao Curso como um veículo de expansão da cultura física e artística da capital. 
Figura 01 - Alunas uniformizadas em pose. Década de 1950.

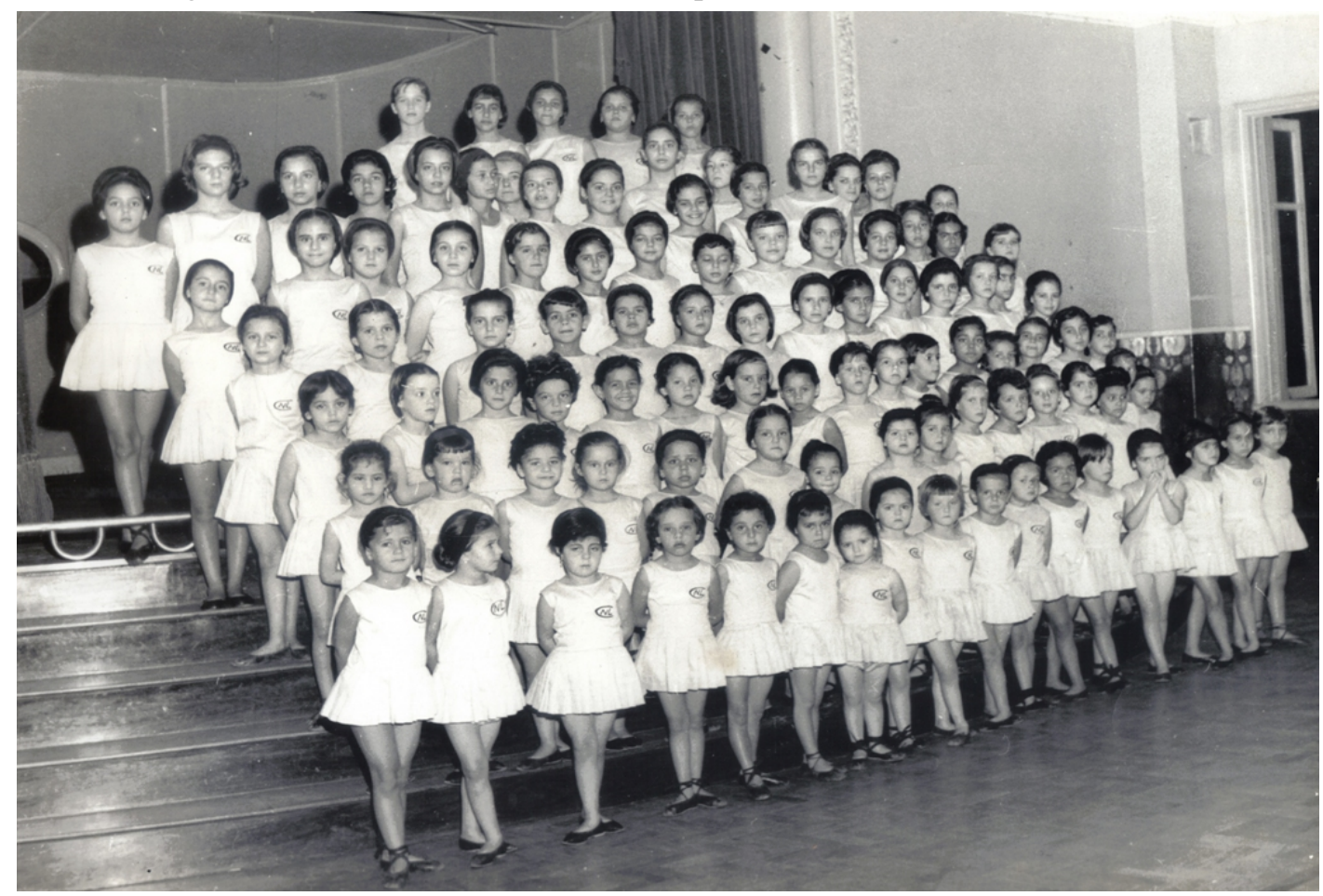

Fonte: Acervo pessoal Martha Lessa

O lugar do Curso na sociedade da ainda jovem capital mineira circula, nesse periódico e em outros, sempre de forma elogiosa, com caráter missionário educacional, como diferenciador de avanço e como potencializador da juventude feminina local. Com destacável participação de uma elite econômica e cultural da região central da cidade, alguns nomes famosos e imagens dão a ver asseio, organização, disciplina, e meninas brancas, bem penteadas vestidas com uniformes ou figurinos de boa qualidade e acabamento.

Dentre as práticas promovidas por Natália Lessa estão, além das aulas, as apresentações coreográficas. As apresentações, momentos de expor à sociedade o trabalho desenvolvido, aconteciam em dois formatos: números coreográficos isolados, com a participação de parte das alunas, em eventos e festividades, e a realização dos 
"festivais das alunas do Curso Natália Lessa", um momento de culminância das atividades com várias coreografias e a participação de todas as alunas.

A produção desses festivais justificam em parte as adjetivações recebidas por Natália Lessa em relação a seu pioneirismo e persistência em trabalhar com a dança em Belo Horizonte naquela época. Com locais precários e falta de profissionais para produção de espetáculos, além de coreógrafa por muitas vezes, era ela quem experimentava, criava e definia a cenografia, os figurinos. Superando as dificuldades, buscando soluções próprias, a qualidade estética dessas apresentações é destacada nas fontes, apreciada pela beleza dos figurinos, cenários e graça das crianças. Seu nível de exigência na produção desses momentos fez do apuro dos detalhes uma garantia de qualidade estética, ainda pouco conhecida pela população em trabalhos artísticos locais. Outro fator muito elogiado era o acompanhamento musical das coreografias, realizado por músicos de destaque na cidade:

\begin{abstract}
As músicas das apresentações de dança de Natália eram ao vivo. Seu orquestrador e arranjador era o maestro José Torres, com a presença de grandes músicos como Vespasiano (pianista), Strambi (violinista), Juvenal (flautista) e outros nomes destacados da época. A cenografia era de Ari Caetano, e até Maura Moreira, o mais consagrado soprano mineiro, que reside na Alemanha, já figurou em seus espetáculos $(\mathrm{O}$ ESTADO DE MINAS, 09 de agosto de 1983, sp. ).
\end{abstract}

Um momento muito recordado pelas ex-alunas são os ensaios gerais, realizados no local do festival. Na ocasião se reuniam todas as participantes, mais as mães e acompanhantes para a preparação final da apresentação. Assim como suas aulas, também suas coreografias compunham um espetáculo diverso, múltiplo em expressões. Cláudia Lessa, sobrinha e aluna de Natália Lessa, declara em entrevista concedida a Arnaldo Alvarenga:

Os festivais eram mistos; ela fazia coisas diferentes. No Teatro Francisco Nunes, nós entrávamos e duas filas, segurando bandeiras 
em que estava escrito 30 anos do curso Natália Lessa. Íamos marchando e subindo pelas laterais até o palco. Coisas assim que a gente não vê em escolas de dança: marcha pelo meio, fazia serenatas, músicas antigas. (LESSA, 2001, apud, Programa de história oral FAFICH/UFMG, 2001 ).

As criações coreográficas de Natália Lessa agregavam as influências de sua formação, seu vínculo com a ginástica e com a educação. No período sob domínio do Estado Novo e do pensamento nacionalista, traduziam-se na valorização da "nossa terra", nas expressões e danças inspiradas na cultura brasileira. Fizeram parte desse conjunto também as expressões americanas que dominavam os cinemas. O cinema, os musicais americanos, eram muito apreciados por ela, frequentadora assídua dos cinemas da cidade e que fez dessa admiração uma fonte de inspiração para suas montagens coreográficas. Em entrevista concedida a Carla Andrea Silva Lima, Ana Lúcia de Carvalho se referindo à diversidade de seu ensino de dança ressalta:

[...] Além disso, ela dava sapateado americano. Porque a Natália foi de uma época onde Shirley Temple era o sucesso. Então ela via muitos filmes, muita coisa, e assimilava tudo muito bem. Passava aquilo para as alunas muitíssimo bem (CARVALHO, 2010, p. 30).

A participação de meninos nos festivais foi identificada em um festival de 1956, onde eram personagens centrais da história tema "A loja de Brinquedos". Mas a representação masculina nas coreografias foi registrada em várias fotografias, onde podemos perceber meninas caracterizadas de homens, compondo casais. As temáticas coreográficas concentram uma concretude em suas formas e figurinos. Inspiram povos e culturas, profissões, objetos; enfim, temas concretos, sem subjetividades. Representações mimetizadas e reinterpretadas que não reduzem ou minimizam a diversidade de suas práticas. O ecletismo coreográfico de seus festivais pode ser 
observado através das fotografias e da análise dos programas dos Festivais, como o de 1943, realizado no Cine Teatro Brasil:

\section{Primeira Parte}

1)Desfile - Hino do curso

2)Ginástica com pandeiros (1 período)

3)Ginástica Interpretativa ( 2 período)

Segunda Parte

1)Fantasia Hindú (movimentos imitativos) 1 período

2)Pastorinhas estilisadas (dansa em ponta) 2 período

3)Escrava (interpretação do Prelúdio de Rachmaninoff), Ex-aluna Maria do Carmo Gonçalves

4)Bonequinhas de antanho (rudimento em ponta) 1 período

5)Princezas do Tirol (sapateado fantasia) 2 período

6) Valsa das Flores de Tschaikowsky, Ex-alunas e solo por Ceci Tompa

7)Dansarina (valsa em ponta pela menina Sonia T. Leite -5 aulas)

8) Pele Vermelha (típico) Ex-alunas

9) Deus Salve a América (alegoria) 2 período.

(PROGRAMA DO FESTIVAL do Curso Natália Lessa, 1943)

A abertura do festival com desfile e hino do curso retrata a proximidade de Natália Lessa às práticas escolares e esportivas. Atípica para espetáculos de dança, esse tipo de manifestação, comum aos grandes jogos, fez parte das tradições do Curso, tanto que foi criado um hino e uma bandeira do Curso. Martha Lessa, sua afilhada e sobrinha, se recorda dos versos:

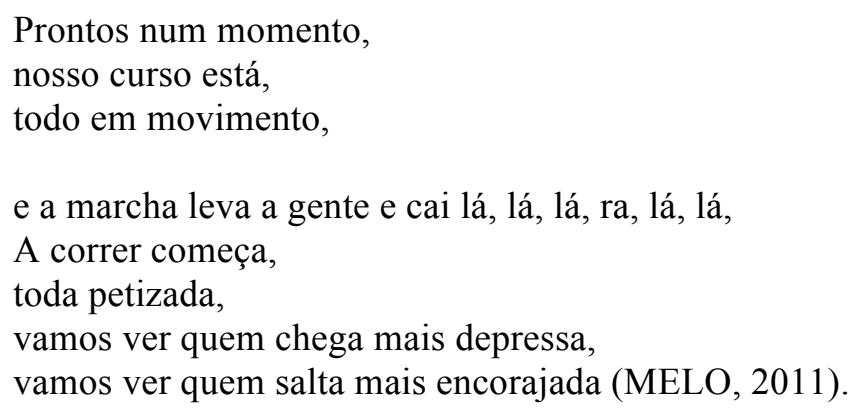

Com versos sem conotação direta à dança, o hino apresenta elementos das práticas corporais da educação física, como a marcha, a corrida. Além dos ritos de energia e vigor da boa saúde dos tempos modernos, como "prontos num momento", 
"chegar mais depressa" e "saltar mais encorajada". Esse hino, quando cantado em apresentações, era acompanhado pelo desfile das alunas em marcha com uma bandeira do Curso.

Misturando tradições do balé clássico, com tradições regionais, vinculadas ao folclore, por vezes denominada por ela como típico, além da presença da ginástica e de temas inspirados nos cinemas, como "Deus salve a América", seus festivais eram momentos muito apreciados na cidade. Irma Volpe, ao ser indagada sobre os festivais, declara:

Vi vários, ao monte. [...] desde meninas pequenininhas de 3 anos, me parece, até as ex-alunas dela, que faziam a parte final. Me parece no final, por exemplo, antes da apoteose, tinha as ex-alunas dela, então eram uns festivais uma gracinha. Os figurinos, muito, de muito bom gosto. Eu quando fantasiava no carnaval, às vezes eu tirava a fantasia da Natália, sabe eu ia lá para poder copiar. A Natália me dava, às vezes até me dava algum adereço assim, leva isso para você, para a sua fantasia, eu tirava a idéia. Era cheio, todo festival da Natália, toda apresentação era muito cheio e isso eu lembro muito bem (VOLPE, 2012).

As criações coreográficas em diferentes estilos de dança variavam nos festivais, ora com uma temática como a "A Loja de Brinquedos", em 1956, ora livre com um conjunto de coreografias sem vinculação, como no programa anteriormente citado, de 1943. Nas fontes não foram localizadas notas de divulgação desses festivais. Martha Lessa, recorda que a madrinha e professora não fazia publicidade do curso; as atividades eram sempre deflagradas com base nas famílias das alunas. Assim, a divulgação de "boca em boca" e a presença da maioria do público era vinculada a essa rede de familiares das alunas. Na Revista Alterosa aparecem fotografias com a identificação do acontecimento, após sua realização, como que dando notícia do que aconteceu na vida social da cidade, mas nunca divulgação prévia. Martha Lessa nos traz informações em 
relação a como se procedia à distribuição de ingressos, no tempo em que era aluna, a partir dos anos 50:

Olha, ela distribuía para as alunas ingressos para vender, mas não tinha nada. Vendeu, vendeu, se não vendeu devolve e ela sempre dava, mas ela pedia para a gente vender, porque o que vendesse iria para a instituição ... era sempre cheio, era muita criança e ela pagava uma festa, tinha uma festa, eu dancei muito na festa na época dela (LESSA, 2012)

Os festivais geravam uma renda, mas segundo os relatos das entrevistas ela nunca ficava com lucro, pois fazia dele uma doação para obras de caridade. No ano de 1943, o festival do programa citado anteriormente, por exemplo, a arrecadação dos ingressos foi destinada à construção da Catedral de Belo Horizonte. No verso do programa vinham as seguintes mensagens:

A construção da Catedral de Belo Horizonte, que ora empreendemos, é insofismavelmente, uma obra de fé; toda fé indômita do povo mineiro está nela empenhada.

Como vacilar sobre o pleno êxito da construção da Catedral Metropolitana? Não é o Divino Mestre quem nos assegura nada ser impossível aos que teem fé?

(PROGRAMA DO FESTIVAL do Curso Natália Lessa, 1943)

Era o momento em que os familiares podiam apreciar suas meninas e ao mesmo tempo expô-las. Esses momentos ampliaram as opções de entretenimento local, envolvendo além das alunas e suas famílias, apreciadores que prestigiavam os momentos de exposição do trabalho desenvolvido. Portanto, além do trabalho educacional ao qual Natália Lessa se dedicou no ensino da dança para as meninas, também propagou na formação de plateias, no entretenimento cultural, na educação estética da capital mineira ainda pouco acostumada com espetáculos produzidos a partir de sua comunidade. Como cita Cynthia Greive, 
A educação estética, tal como é compreendida na modernidade, é parte do contexto de valorização das culturas nacionais e, ao mesmo tempo, da valorização do sujeito autônomo, individualizado e racionalizado, que por isso é capaz de se identificar com os princípios e valores universalizados, necessários à harmonia social. Nas primeiras décadas republicanas, observa-se uma forte preocupação não somente com a produção estética mas também com a produção da recepção estética, uma vez que na concepção das elites a população era "gente sem qualquer cultivo" (VEIGA, 2000, p. 409). ${ }^{6}$

Entendemos que o apelo à caridade na destinação dos fundos às obras sociais ou religiosas também se tornava um atrativo nobre para a grande audiência que registravam os festivais. Uma boa causa para o envolvimento da tradicional família mineira, e um elegante entretenimento na cidade. No Jornal O Estado de Minas, em 1983, na comemoração dos 50 anos de fundação do Curso de Natália Lessa, o jornalista José Maurício registra: "Nunca seus espetáculos foram em benefício da própria escola, todos foram em caráter beneficente."

Em Belo Horizonte o Teatro Municipal, inaugurado em 1909, foi demolido com intuito da construção de uma moderna edificação iniciada em 1941 e que só se efetivou em 1986. A carência de espaços teatrais faz parte da história de Belo Horizonte. Nesse meio tempo as apresentações de artes cênicas na cidade ocuparam outros espaços, como os cinemas e os auditórios. Natália Lessa, como referencia Arnaldo Alvarenga (2002), buscou a diversificação de espaços para apresentações de suas alunas. A circulação de apresentações em diferentes espaços na cidade e por diferentes motivações foram agregando popularidade às atividades do Curso, ao nome da professora e à dança como prática corporal feminina apreciada. Elas aconteciam nos cinemas, antes da exibição de filmes, como o Cine Brasil, o Tupi e o Metrópole, no antigo Teatro Municipal, em

\footnotetext{
${ }^{6}$ Cynthia G. VEIGA, dando continuidade a essa citação, apresenta nos dizeres de um dos membros da Comissão Construtora de Belo Horizonte, o seguinte comentário: “[...] Não primam as cidades e povoados de Minas por belezas artísticas de qualquer espécie: o homem parece até hoje alheio ao instinto do belo. [...] O conforto do corpo e o encanto do espírito não tinham até hoje entrado como fatores nestes problemas da vida [...].( MINAS GERAIS, apud, VEIGA, 2000, p.409).
} 
programas da TV Itacolomi, no Instituto de Educação, no Grupo Escolar Barão do Rio Branco, nos Teatros Francisco Nunes e Marília, nos clubes, como o Minas Tênis e o Belo Horizonte, em eventos organizados pela alta sociedade local, ocasiões e espaços que possibilitaram a experiência cênica de suas alunas e a apreciação estética do público que acompanhava as apresentações de números isolados ou dos festivais completos. Para termos uma média de público, dentre os espaços onde eram realizados os festivais, o Teatro Francisco Nunes, por exemplo, possuía capacidade para 600 pessoas. Foi inaugurado em 1950, com o nome de Teatro de Emergência, pois o Teatro Municipal se transformou em Cine Metrópole e o Palácio das Artes, que seria a substituição do Municipal, ainda estava em complicadas obras. Emergencialmente foi construído dentro do parque municipal o Teatro Francisco Nunes. À época Belo Horizonte tinha uma média de 352.000 habitantes, ou seja, uma lotação de 600 pessoas representava cerca de $2 \%$ da população local por dia de apresentação, que era variável (1 ou 2 dias), mais as alunas, que eram aproximadamente 100.

Ana Lúcia de Carvalho foi aluna de Natália Lessa de 1950 a 1962; ao se recordar dessas apresentações ela relata:

Dancei muito nos cines Tupi e Metrópole revezando com a TV Itacolomi quase todos os domingos num programa do Frei Martinho Bournier. Isto era todos os domingos. Como não tinha tutus dançava com meus vestidos comuns, lindos, extremamente rodados, barrados, plissados, rendados como pedia a época. Eu me sentia ótima e isto me inspirava (CARVALHO, 2010, p. 25).

Os festivais eram realizados com música ao vivo, orquestras regidas por maestros famosos. Nós pegamos o início da TV Itacolomi e éramos convidados para dançar em programas ao vivo quase toda semana (CARVALHO, 1997 ).

As apresentações não se limitavam à capital. Natália Lessa viajava com suas alunas para o interior do Estado. As fontes sobre essas viagens estão centradas nos 
relatos das alunas e nas citações em jornais após o período analisado, sem periodicidade, elenco ou coreografias apresentadas. O que podemos atestar é que acompanhada de uma assistente e algumas mães, ela organizava essas viagens para o interior do Estado, onde eram hospedadas em casas de famílias e faziam apresentações a convite da cidade ou de instituições locais. Em relação a essas viagens e a potencialidade que elas parecem ter tido na perspectiva de divulgação do curso e da dança como prática corporal feminina compreendemos uma espécie de missão educacional e cultural de levar ao interior as modernas práticas da capital. Esses momentos eram promotores de uma experiência única, essencialmente feminina que, por meio desses eventos ausentavam-se de sua cidade, conhecia outras localidades, apresentavam-se como artistas da capital, ainda que infantis, e provavelmente sem consciência da dimensão de ser "modelar", de ser representação de um ideário, referência de um tempo onde modos e formas de civilidade feminina recebiam uma valorização.

Natália Lessa também ministrava aulas em alguns desses lugares, além de apresentar suas alunas. Segundo os relatos das alunas, essas atividades não eram permanentes, mas aconteciam desde a década de 1940, como no caso de Maria José Lemos, que se apresentou em Uberaba, por volta de 1947. Dentre as cidades visitadas são citadas: Diamantina, Uberaba, Mariana, Conselheiro Lafaiete, Itabirito, Passos, Acesita, Ipatinga, Viçosa, Ouro Preto, Formiga, Itabira, Ubá, Muriaé, Nova Lima.

Assim foram disseminadas representações, ambiguidades, particularidades e ideários através das expressões de meninas que, na dança, aprendiam e ensinavam como ser feminina em um dado tempo e espaço. 
O resgate das práticas de Natália Lessa em sala de aula e nas apresentações pela

cidade forjou duas dimensões complementares e consequentes. $O$ espaço de aprendizagem e o espaço de divulgação da aprendizagem. Todo o processo educacional proposto por ela nas aulas vinculava-se à culminância das apresentações coreográficas. Uma prática que fomentou a formação de plateias seja nos teatros ou em outros espaços de apresentação, e a apreciação da dança através da divulgação nas revistas e jornais, onde os belorizontinos podiam ver suas meninas expostas como exemplares de um futuro desejável.

\section{REFERÊNCIAS}

ALVARENGA, Arnaldo Leite de. Dança Moderna e Educação da Sensibilidade: Belo Horizonte (1959-1975). Belo Horizonte, 2002. Dissertação (Mestrado em Educação) - Faculdade de Educação, Universidade Federal de Minas Gerais, Belo Horizonte, 2002.

BENJAMIN, Walter. Magia e técnica, arte e política: ensaios sobre literatura e história da cultura. São Paulo: Brasiliense, 1996.

CARVALHO, José Murilo de. Pontos e Bordados. Belo Horizonte: Editora da UFMG, 1999.

A EDUCAÇÃO physica entre as moças: O ESPORTE visita o curso "Nathalia Lessa". O Esporte, Belo Horizonte, 19 de outubro, 1936, n. 1, p.1.

FARIA FILHO, Luciano Mendes de. História da escola primária e da educação física no Brasil: alguns apontamentos. In: SALVADORA, Eustáquia; VAGO, Tarcísio M.(Org.).Trilhas e partilhas: educação física na cultura escolar e nas práticas sociais. Belo Horizonte: Cultura, 1997.

MAURÍCIO, José. Natália Lessa: 50 anos de balé. Estado de Minas, Belo Horizonte, 09 de agosto de 1983.

MORAIS, Frederico; SANTIAGO, Evandro. Ensinar ballet cansa muito e compensa pouco. Diário da Tarde, Belo Horizonte, 05 de setembro de 1960. Segundo CadernoSérie: $O$ ballet e a cidade, p.2.

MORENO, Andrea; VAGO, Tarcísio Mauro. Nascer de novo na cidade jardim da República: Belo Horizonte como lugar de cultivo de corpos (1891-1930). Revista ProPosições, Campinas, v.22, n.3, set/dez 2011. 
A MULHER mineira no esporte. Revista Alterosa, v.3, n. 22, 1942, p.30.

NUNES, Clarice. (Des) encantos da modernidade pedagógica. In: LOPES, Eliane Marta Teixeira; FARIA FILHO, Luciano Mendes de; VEIGA, Cynthia Greive. (Org.). 500 anos de Educação no Brasil. Belo Horizonte: Autêntica, 2000. p. 371-398.

ONDE E QUANDO - Revista Guia de Belo Horizonte, v. 1, n. 4, agosto, 1949.

PESAVENTO, Sandra J. História e História Cultural. Belo Horizonte: Autêntica, 2005.

\begin{tabular}{llll}
\multicolumn{4}{c}{ Sensibilidades no tempo, tempo das sensibilidades. Nuevo. Mundo Mundos } \\
Nuevos, & Número & $4-2004$ & Disponível
\end{tabular} https://nuevomundo.revues.org/document229.html. Acesso em: 06 mar. 2013.

PINTO, Nilo Aparecida. O esplender cultural de Belo Horizonte. Revista Alterosa, v. 6, n. 53, set., 1944, p. 72-76.

PROGRAMA DO FESTIVAL do Curso Natália Lessa, 1943.

PROGRAMA DO FESTIVAL do Curso Natália Lessa. A loja de Brinquedos, 1956.

REIS, Glória. Natália Lessa, uma vida para dança. Belo Horizonte, 2010.

SANTOS, Jorge Fernando dos. BH em cena: "teatro, televisão, ópera e dança na Belo Horizonte centenária”. Belo Horizonte: Del Rey, 1995.

SILVA, Pe. Willian. Alunas de dança homenageiam Dona Natália Lessa. O Diário, Belo Horizonte, 17 de setembro, 1960, p.5.

SOARES, Carmem Lúcia. Corpo, conhecimento e educação: notas esparsas. In:

(Org.) Corpo e história. Campinas: Autores Associados, 2006. p. 109-130.

VEIGA, Cynthia Greive. Educação estética para o povo. In: LOPES, Eliane Marta Teixeira; FARIA FILHO, Luciano Mendes de; VEIGA, Cynthia Greive. (Org.). 500 anos de Educação no Brasil. Belo Horizonte: Autêntica, 2000. p. 399-422.

\section{Endereço da Autora:}

Elisângela Chaves

EEFFTO/UFMG

Av. Antônio Carlos 6627 - Pampulha

Belo Horizonte - MG - 31.270-901

Endereço Eletrônico: elischaves@ufmg.br 